\title{
Stroke caregiver information needs: Comparison of Mainland and Puerto Rican caregivers
}

\author{
Melanie Sberna Hinojosa, PhD; ${ }^{1-2 *}$ Maude R. Rittman, RN, PhD ${ }^{1,3}$ \\ ${ }^{1}$ North Florida/South Georgia Veterans Health System, Rehabilitation Outcomes Research Center, Gainesville, FL; \\ ${ }^{2}$ Department of Sociology and ${ }^{3}$ College of Nursing, University of Florida, Gainesville, FL
}

\begin{abstract}
Research indicates that informal caregivers of stroke survivors often do not have the information necessary to adequately manage the recovery process at home. This article presents findings on the information sources and needs of stroke caregivers both in Puerto Rico and the Mainland United States. Data were collected from 120 caregivers (42 Puerto Rican, 78 Mainland) of veterans who had experienced a stroke. Of all caregivers, $22 \%$ to $50 \%$ reported the need for information related to stroke recovery. This need was greater for Puerto Rican caregivers compared with Mainland caregivers. Caregivers receive most of their information from their doctors, the Veterans Health Administration (VHA), and the Internet. This study highlights the need for information dissemination to Puerto Rican and Mainland caregivers within the VHA system. This dissemination is an important and ongoing goal of the Stroke Quality Enhancement Research Initiative and the VHA/ Department of Defense Clinical Practice Guidelines.
\end{abstract}

Key words: caregivers, education, educational materials, informal caregiving, informational materials, Mainland United States, Puerto Rico, rehabilitation, stroke, stroke caregiving, stroke information.

\section{INTRODUCTION}

\section{Stroke}

Stroke is the leading cause of serious long-term disability, affecting more than 4 million people in the United States [1-3]. Approximately 80,000 veterans receiving healthcare in the Veterans Health Administration (VHA) are stroke survivors and an estimated 9,000 to 11,000 veterans are hospitalized each year with a new stroke [4-5]. Compared with whites, Latinos and other minority groups in the United States have a greater incidence and mortality from stroke, especially those who are younger and in the lower socioeconomic tiers [2,6-9]. Latino stroke patients are twice as likely as whites to have a recurrent stroke within 2 years of their first stroke [10]. Significant differences exist among Latino subgroups, indicating higher levels of stroke mortality among Puerto Ricans than Cuban Americans or Mexican Americans, though the reasons for these differences are not completely understood [11]. In addition, postacute disability from stroke is higher among Latinos compared with whites [12].

The burden of stroke is linked to socioeconomic status (SES). Racial/ethnic minorities in the United States on average have a lower SES compared with whites, and SES is a good predictor of not only stroke but also overall health. Lower SES is associated with lower life expectancy and greater incidence of and more frequent exposure

Abbreviations: $\mathrm{ADL}=$ activity of daily living, $\mathrm{FY}=$ fiscal year, FSOD = Functional Status Outcomes Database, SES = socioeconomic status, VA = Department of Veterans Affairs, VHA = Veterans Health Administration.

*Address all correspondence to Melanie S. Hinojosa, PhD; Medical College of Wisconsin, Center for Healthy Communities, 8701 Watertown Plank Road, PO Box 26509, Milwaukee, WI 53226; 414-456-4095, fax: 414-45-6523.

Email: mhinojosa@mcw.edu

DOI: $10.1682 / J R R D .2006 .10 .0131$ 
to risk factors associated with stroke [13]. Men and women of lower SES have greater stroke mortality. Evidence exists that Latinos with lower educational and income levels are prone to higher rates of stroke [9].

\section{Stroke Caregiving}

Nearly 80 percent of stroke survivors are discharged home with the responsibility of continuing care and recovery shifting to informal caregivers, often family members with little or no preparation or training [14]. The number of noninstitutionalized stroke survivors has been increasing over time, implicating greater family care burden. Informal caregivers face difficulties such as uncertainty, anxiety, depression, poorer health, and poor quality of life because of the sudden onset of stroke and the new caregiver role [15-17].

Presence of a competent, knowledgeable caregiver is a critical determinant of whether a stroke survivor's mental and physical health improve and whether he or she is institutionalized or remains at home or in the community [18]. Latino caregivers, because of cultural and familial differences, are less likely to institutionalize those in their care or may delay institutionalization the longest compared with other racial/ethnic groups [19]. Latino caregivers also are more likely to be family members, report a greater sense of duty toward older persons in their care, and spend more hours on informal care compared with other racial/ethnic groups [20-22].

Research demonstrates that stroke survivors and their caregivers often lack the information necessary to help manage the recovery process at home [23-24]. Many stroke caregivers lack basic information about strokes, strategies for caring for stroke survivors, and ways to prevent complications and future strokes. Although the VHA/Department of Defense Clinical Practice Guidelines for Management of Stroke Rehabilitation emphasize the importance of patient and family/caregiver education, stroke survivors and their families often voice dissatisfaction with the information provided to them by healthcare providers and lack basic knowledge about stroke and prevention of future strokes [25]. The information that caregivers do receive is often not tailored to individual needs, creating a gap in meeting the needs of this group [26].

Assessing the information needs of Puerto Rican stroke caregivers is particularly important given that Latinos have greater poststroke disability, greater risk of recurrent stroke, and spend more time in the caregiving role [27]. Currently, the Department of Veterans Affairs (VA) Caribbean Health Care System in San Juan, Puerto Rico, sees the second highest volume of stroke patients of all VAs in the United States. Given this disparity, caregivers living in Puerto Rico may, as a group, differ in their needs for information about managing stroke recovery at home.

This article, as part of a larger study of caregivers of stroke survivors, examines the level of information caregivers need, what information they initially receive, and what sources they use to obtain information to assist in the recovery process at home. Given the disparities in stroke burden, we also assess how these levels vary by Puerto Rican caregivers living on the island of Puerto Rico compared with Mainland U.S. caregivers of veterans who have had an acute stroke.

\section{METHODS}

\section{Participants}

Caregivers for the sample were drawn from the population of veterans who had experienced a new, first-time stroke in fiscal year (FY) 2003, 2004, or 2005 in Veterans Integrated Service Networks 8 (Florida, parts of Georgia, and Puerto Rico), 11 (parts of Michigan, northern Illinois, and Indiana), and 15 (parts of Kansas, Missouri, and southern Illinois). We identified veterans and caregivers from VHA inpatient databases and the Functional Status Outcomes Database (FSOD) using Reker's high sensitivity and high specificity diagnostic algorithms [28]. Reker's high sensitivity and high specificity algorithms were developed with cerebrovascular-related International Classification of Diseases-9 codes for identifying veterans with acute stroke in automated VHA data. To be eligible, caregivers had to (1) verify that they provide assistance to the veteran with at least one activity of daily living (ADL) or instrumental ADL and (2) consent to participate in a telephone survey. Caregivers were invited to participate if they were caring for a veteran who (1) had experienced a first time stroke in FY2003, 2004, or 2005 and met the criteria for the high specificity or high sensitivity algorithms with a verified stroke diagnosis in their clinical record and (2) lived in the community.

A total of 149 caregivers identified from the databases met the initial criteria and 120 completed the survey. Of the 29 who did not complete the survey, 13 refused, 14 could not be reached at the telephone number given, 
and 2 were ineligible. The response rate of Mainland caregivers was 78 percent, slightly lower than the 85.7 percent response rate of Puerto Rican caregivers. The overall response rate for the survey was 81.9 percent. Analyses were conducted on 42 caregivers living in Puerto Rico and 78 caregivers living in the Mainland United States (whites and African Americans ${ }^{*}$ ).

\section{Procedures}

As part of a larger survey, caregivers reported their information needs and the degree to which those needs had been met. Items included clinical and social aspects of managing the caregiving role and the stroke recovery process at home. Information was also collected on age, sex, relationship to veteran, educational level, living arrangements, caregiving hours, caregiver burden, and health status. Surveys were conducted by expert telephone surveyors contracted through the University of Florida Survey Research Center in collaboration with our investigators and with oversight from our research team. All telephone surveys were conducted with $\mathrm{Ci} 3$ computerassisted telephone interview software (Sawtooth Software, Inc; Sequim, Washington) that incorporates sophisticated programming for consistency checking, skip patterns, and ongoing quality assurance. The VHA Sub-

\footnotetext{
*We determined through initial analyses that whites and African Americans living in the Mainland United States did not significantly differ on sociodemographics such as age, sex, relationship, and education. For this reason, we treat Mainland whites and African Americans as one group.
}

committee on Clinical Investigation, the VA Research and Development Committee, and the University of Florida Health Science Center Institutional Review Board approved the study.

\section{Measurement}

\section{Caregiver Information Needs}

Our survey queried caregivers about the skills and information they need to manage the caregiving role and whether they received information or training to help them manage the caregiving role. Table 1 displays several content domains that center on clinical and social aspects of the stroke caregiving experience.

Three variables were created from each of the survey items in Table 1: information needs, information received, and the gap between the need for and the receipt of information. Caregivers were asked to respond "yes" or "no" to each of the survey items, first, if they needed the particular information, and, second, if they received the particular information. A third variable, based on the difference of the first and, second variables, measured the gap between those individuals who reported a need for information and those who actually received that information.

\section{Caregiver Information Sources}

Caregivers were asked to indicate where they obtained information pertaining to each aspect of caring for stroke survivors. They were asked two questions about sources of health information. First, they were specifically

Table 1.

Survey items.

\begin{tabular}{|c|c|}
\hline Information Area & Survey Items \\
\hline Clinical Aspects of Stroke Caregiving & $\begin{array}{l}\text { Stroke, risk of second stroke. } \\
\text { Help with communication because of speech impairment. } \\
\text { Managing behavior (falling, crying, depression). } \\
\text { Managing privacy issues (cleaning, bathing). } \\
\text { Moving or lifting veteran. } \\
\text { Functional changes following stroke. } \\
\text { Prescriptions, medications, side effects. } \\
\text { Safety at home. }\end{array}$ \\
\hline Social Aspects of Stroke Caregiving & $\begin{array}{l}\text { Protecting from those wanting to take advantage. } \\
\text { Managing emotional ups and downs. } \\
\text { Getting financial help. } \\
\text { Changes in relationship with veteran. } \\
\text { Changes in veteran relationship with family. }\end{array}$ \\
\hline
\end{tabular}


asked whether they had ever used the VHA Internet Web site MyHealtheVet to obtain information. Responses were coded as $1=$ yes and $0=$ no. Second, caregivers were asked where they would turn if they were looking for information about some aspect of stroke caregiving. Caregivers were allowed to answer anyway they chose and answers were categorized as doctor; nurse/other health professional; Internet; books, magazines, library; employer; senior center; VA; family; friend; religious organization; or other.

\section{Data Analysis}

First, we examined the demographic characteristics of our sample and performed $t$-tests and chi-square tests to compare across Mainland and Puerto Rican caregivers. Next, we used frequency counts and proportions to provide a descriptive picture of information needs, gaps, and sources. Finally, we used chi-square analyses to examine differences in proportions of needs, gaps, and sources between Mainland and Puerto Rican caregivers.

Because of the low cell sizes in the contingency tables for the data, we used a two-tailed Fisher exact test.
This procedure gives exact results for $2 \times 2$ tables in which the standard $\chi^{2}$ is not applicable.

\section{RESULTS}

\section{Caregiver Characteristics}

Table 2 summarizes the characteristics of the caregivers in our sample. Most caregivers were female (92.5\%) with an average age of 61.6 years. Caregiver relationships to veterans were mostly familial, with 73.3 percent caring for spouses or partners, 6.7 percent caring for children, 4.2 percent caring for parents, 2.5 percent caring for siblings, 0.8 percent caring for other family, and 12.5 percent caring for others. We found that 69.0 percent of caregivers had at least a high school diploma, 89.2 percent lived with the veteran, and they spent an average of 35.8 hours a week providing care. One measure of caregiver burden is the number of ADLs with which a caregiver assists the stroke survivor. Caregivers provided assistance with an average of 2.9 ADLs. Most caregivers reported being in good health, with 11.0 percent reporting excellent health,

Table 2.

Characteristics of stroke caregivers in sample.

\begin{tabular}{|c|c|c|c|}
\hline Characteristic & $\begin{array}{l}\text { All Caregivers } \\
\qquad(N=120)\end{array}$ & $\begin{array}{l}\text { Mainland } \\
(n=78)\end{array}$ & $\begin{array}{l}\text { Puerto Rico } \\
\quad(n=42)\end{array}$ \\
\hline Age (mean \pm SD) & $61.6 \pm 11.6$ & $61.2 \pm 11.0$ & $62.4 \pm 12.7$ \\
\hline Female (\%) & 92.5 & 89.7 & 97.6 \\
\hline Spouse/Partner ${ }^{*}$ & 73.3 & 69.2 & 81.0 \\
\hline Child & 6.7 & 6.4 & 7.1 \\
\hline Other Family & 0.8 & 1.3 & 0.0 \\
\hline Other & 12.5 & 19.2 & 0.0 \\
\hline High School Graduate (\%) ${ }^{\dagger}$ & 69.0 & 81.3 & \\
\hline Lives with Veteran (\%) & 89.2 & 87.2 & 92.9 \\
\hline Very Good & 21.2 & 20.5 & 22.5 \\
\hline Good & 34.8 & 38.5 & 27.5 \\
\hline Fair & 25.4 & 23.1 & 30.0 \\
\hline Poor & 7.6 & 9.0 & 5.0 \\
\hline
\end{tabular}


21.2 percent reporting very good health, 34.8 percent reporting good health, 25.4 percent reporting fair health, and 7.6 percent reporting poor health.

Mainland caregivers differed from Puerto Rican caregivers in their relationship to the veteran, their educational level, and the number of hours they spent each week providing care. Mainland caregivers spent fewer hours per week (25.2 hours) compared with Puerto Rican caregivers (54.8 hours) $(t=-2.91, p=0.006)$. A greater proportion of Mainland caregivers had received a high school diploma (81.3\%) compared with Puerto Rican caregivers $(46.3 \%)(t=3.85, p<0.001)$. Different patterns of family relationships between caregiver and veteran were evident in Mainland caregivers compared with Puerto Rican caregivers $\left(\chi^{2}=13.60, p=0.018\right)$.

\section{Caregiver Information Needs}

Table 3 summarizes the proportion of all caregivers who needed and/or received information regarding clinical and social aspects of stroke recovery and caregiving. The numbers in the first two columns represent the proportion of all caregivers reporting the need for and the receipt of information, respectively. Data in the final column represent the gap between information needs and receipt.

The proportion of caregivers who reported needing information related to clinical aspects of stroke caregiving ranged from 15.3 to more than 50 percent. The greatest proportion of caregivers (51.3\%) reported needing information on stroke and stroke risk, followed by prescriptions or medications (41.2\%), managing behavior (36.4\%), safety at home (33.6\%), functional changes (30.4\%), communication (18.5\%), moving or lifting (15.4\%), and managing privacy issues (15.3\%). The proportion of caregivers who reported needing information related to social aspects of stroke caregiving ranged from 22.2 to 35.9 percent. The highest percentage of caregivers reported needing information about managing emotional ups and downs (35.9\%), followed by getting financial help (30.0\%), protecting the veteran (26.9\%), and changes in family relationships (22.2\%).

Smaller numbers of stroke caregivers reported receiving information about stroke caregiving, with less than 37 percent receiving any information at all. Of the clinical information received by caregivers, the greatest amount of information was received about stroke and stroke risk (36.7\%), followed by prescriptions or medications (29.2\%), functional changes (20.8\%), safety at home $(10.0 \%)$, managing behavior $(7.5 \%)$, communication (6.7\%), moving or lifting (5.8\%), and managing privacy issues (5.8\%). Information about social aspects of caregiving was received in even smaller numbers. Caregivers received the most information about getting financial help (13.3\%), followed by managing emotional ups and downs $(9.2 \%)$, changes in family relationships (8.3\%), and protecting the veteran (5.0\%).

Table 3.

Information needs for all stroke caregivers $(N=120)$.

\begin{tabular}{|c|c|c|c|}
\hline Information Area & $\begin{array}{l}\text { \% Needing } \\
\text { Information }\end{array}$ & $\begin{array}{l}\text { \% Receiving } \\
\text { Information }\end{array}$ & $\begin{array}{c}\text { \% with Unmet } \\
\text { Needs }\end{array}$ \\
\hline \multicolumn{4}{|l|}{ Clinical Aspects of Stroke Recovery } \\
\hline Stroke, Risk of Second Stroke & 51.3 & 36.7 & 14.6 \\
\hline Help with Communication & 18.5 & 6.7 & 11.8 \\
\hline Managing Behavior (falling, etc.) & 36.4 & 7.5 & 28.9 \\
\hline Managing Privacy Issues & 15.3 & 5.8 & 9.5 \\
\hline Functional Changes & 30.4 & 20.8 & 9.6 \\
\hline Prescriptions/Medications & 41.2 & 29.2 & 12.0 \\
\hline Safety at Home & 33.6 & 10.0 & 23.6 \\
\hline \multicolumn{4}{|l|}{ Social Aspects of Stroke Recovery } \\
\hline Protecting Veteran & 26.9 & 5.0 & 21.9 \\
\hline Changes in Veteran Relationship with Family & 22.2 & 8.3 & 13.9 \\
\hline
\end{tabular}


The proportion of stroke caregivers with unmet needs was calculated from the difference between those who had reported a need for information and those who had received information. Higher percentages represent greater need. The proportion of unmet needs ranged between 9.6 and 28.9 percent for information related to clinical aspects of caregiving and between 13.9 and 26.7 percent for social aspects of caregiving. The largest unmet need with regard to clinical aspects was for managing behavior (28.9\%), followed by safety at home (23.6\%), stroke and stroke risk (14.6\%), communication (11.8\%), prescriptions or medications (12.0\%), moving or lifting (9.6\%), functional changes (9.6\%), and managing privacy issues (9.5\%). The largest unmet need related to social aspects of stroke caregiving was for managing emotional ups and downs (26.7\%), followed by protecting the veteran (21.9\%), getting financial help (16.7\%), and changes in family relationships (13.9\%).

\section{Mainland Versus Puerto Rican Caregivers}

The second part of our analysis compared the proportion of Mainland and Puerto Rican caregivers who needed and received information related to stroke caregiving. Mean, standard deviation, test statistic, and $p$-value results are reported in Tables 4-6 for Mainland and Puerto Rican caregivers.

Table 4 displays the results of Mainland versus Puerto Rican caregivers on their information needs after stroke. Results indicate that Puerto Rican caregivers reported a significantly greater need for information about managing challenging behaviors (61\%) compared with Mainland caregivers (23.4\%) $\left(\chi^{2}=16.33, p<\right.$ 0.001). In addition, Puerto Rican caregivers also reported a significantly greater need for information about keeping the veteran safe at home (59.5\%) compared with Mainland caregivers $(19.5 \%)\left(\chi^{2}=19.53, p<0.001\right)$. Mainland and Puerto Rican caregivers did not differ in the amount of information they needed regarding social aspects of stroke caregiving.

Table 5 displays the results of Mainland versus Puerto Rican caregivers on their receipt of information related to clinical and social aspects of stroke caregiving. Although Mainland and Puerto Rican caregivers did differ on the amount of information they received about clinical and social aspects of stroke caregiving, these differences were not statistically significant.

Table 6 displays the comparison of unmet needs for information related to clinical and social aspects of stroke caregiving for Mainland and Puerto Rican caregivers. Puerto Rican caregivers had a greater unmet need for information about managing behaviors (48.8\%) compared with Mainland caregivers (18.2\%) $\left(\chi^{2}=12.21, p=\right.$ 0.001). Puerto Rican caregivers also had a greater unmet need for information about prescriptions or medications

Table 4.

Information needs of Mainland U.S. $(n=78)$ and Puerto Rican $(n=42)$ stroke caregivers.

\begin{tabular}{|c|c|c|c|c|}
\hline \multirow{2}{*}{ Information Area } & \multicolumn{2}{|c|}{ Caregivers (\%) } & \multirow{2}{*}{ Test Statistic ${ }^{*}$} & \multirow{2}{*}{$p$-Value } \\
\hline & Mainland & Puerto Rico & & \\
\hline \multicolumn{5}{|l|}{ Clinical Aspects of Stroke Recovery } \\
\hline Stroke, Risk of Second Stroke & 50.7 & 52.4 & 0.03 & 0.86 \\
\hline Help with Communication & 16.7 & 22.0 & 0.50 & 0.48 \\
\hline Managing Behavior (falling, etc.) & 23.4 & 61.0 & 16.33 & $<0.001$ \\
\hline Managing Privacy Issues & 14.3 & 17.1 & 0.16 & 0.69 \\
\hline Functional Changes & 28.6 & 34.2 & 0.38 & 0.54 \\
\hline Prescriptions/Medications & 39.0 & 45.2 & 0.44 & 0.51 \\
\hline Safety at Home & 19.5 & 59.5 & 19.53 & $<0.001$ \\
\hline \multicolumn{5}{|l|}{ Social Aspects of Stroke Recovery } \\
\hline Protecting Veteran & 22.1 & 35.7 & 2.57 & 0.11 \\
\hline
\end{tabular}


Table 5.

Information received by Mainland U.S. $(n=78)$ and Puerto Rican $(n=42)$ stroke caregivers.

\begin{tabular}{|c|c|c|c|c|}
\hline \multirow{2}{*}{ Information Area } & \multicolumn{2}{|c|}{ Caregivers (\%) } & \multirow{2}{*}{ Test Statistic ${ }^{*}$} & \multirow{2}{*}{$p$-Value } \\
\hline & Mainland & Puerto Rico & & \\
\hline \multicolumn{5}{|l|}{ Clinical Aspects of Stroke Recovery } \\
\hline Stroke, Risk of Second Stroke & 35.9 & 38.1 & 0.06 & 0.81 \\
\hline Help with Communication & 7.7 & 4.8 & - & 0.71 \\
\hline Managing Behavior (falling, etc.) & 5.1 & 11.9 & - & 0.27 \\
\hline Managing Privacy Issues & 7.7 & 2.4 & - & 0.42 \\
\hline Moving or Lifting & 6.4 & 4.8 & - & $>0.99$ \\
\hline Functional Changes & 18.0 & 26.2 & 1.12 & 0.29 \\
\hline Prescriptions/Medications & 32.1 & 23.8 & 0.90 & 0.34 \\
\hline Safety at Home & 6.4 & 16.7 & - & 0.11 \\
\hline \multicolumn{5}{|l|}{ Social Aspects of Stroke Recovery } \\
\hline Protecting Veteran & 5.1 & 4.8 & - & $>0.99$ \\
\hline Managing Emotional Ups and Downs & 9.0 & 9.5 & - & $>0.99$ \\
\hline Getting Financial Help & 12.8 & 14.3 & 0.05 & 0.82 \\
\hline Changes in Relationship with Veteran & 10.3 & 4.8 & - & 0.49 \\
\hline Changes in Veteran Relationship with Family & 7.7 & 9.5 & - & 0.74 \\
\hline
\end{tabular}

Table 6.

Gaps in information needed and information received by Mainland U.S. $(n=78)$ and Puerto Rican $(n=42)$ stroke caregivers.

\begin{tabular}{|c|c|c|c|c|}
\hline \multirow{2}{*}{ Information Area } & \multicolumn{2}{|c|}{ Caregivers (\%) } & \multirow{2}{*}{ Test Statistic ${ }^{*}$} & \multirow{2}{*}{$p$-Value } \\
\hline & Mainland & Puerto Rico & & \\
\hline \multicolumn{5}{|l|}{ Clinical Aspects of Stroke Recovery } \\
\hline Stroke, Risk of Second Stroke & 14.3 & 14.3 & 0.00 & $>0.99$ \\
\hline Help with Communication & 9.0 & 17.1 & 1.70 & 0.19 \\
\hline Managing Behavior (falling, etc.) & 18.2 & 48.8 & 12.21 & 0.001 \\
\hline Managing Privacy Issues & 6.5 & 14.6 & - & 0.19 \\
\hline Moving or Lifting & 9.3 & 9.5 & - & $>0.99$ \\
\hline Functional Changes & 10.4 & 5.3 & - & 0.49 \\
\hline Prescriptions/Medications & 6.5 & 21.4 & - & 0.03 \\
\hline Safety at Home & 13.0 & 42.9 & 13.48 & 0.002 \\
\hline \multicolumn{5}{|l|}{ Social Aspects of Stroke Recovery } \\
\hline Protecting Veteran & 16.9 & 31.0 & 3.15 & 0.07 \\
\hline Managing Emotional Ups and Downs & 22.4 & 34.2 & 1.90 & 0.17 \\
\hline Getting Financial Help & 16.9 & 16.7 & 0.001 & 0.98 \\
\hline Changes in Relationship with Veteran & 13.2 & 14.6 & 0.05 & 0.82 \\
\hline Changes in Veteran Relationship with Family & 12.8 & 15.4 & - & 0.78 \\
\hline
\end{tabular}

(21.4\%) (Fisher exact test, $p=0.03$ ) and keeping the veteran safe at home $(42.9 \%)\left(\chi^{2}=13.48, p=0.002\right)$ compared with Mainland caregivers $(6.5 \%$ and $13.0 \%$, respectively). As in the previous two analyses, no differences were detected between groups on social aspects of stroke caregiving.

\section{Sources of Caregiver Information}

The final part of our analysis examined the sources stroke caregivers used to obtain information related to clinical and social aspects of stroke caregiving. Table 7 displays the descriptive statistics and results of chisquare and Fisher exact tests comparing Mainland and 
Puerto Rican caregivers. Caregivers got most of their information from doctors (32.5\%) and the VA (30.0\%). Other sources included the Internet (18.3\%); nurses/other health professionals (13.3\%); books, magazines, and libraries (10.8\%); family (8.3\%); friends (4.2\%); religious organizations (3.3\%); the MyHealtheVet Web site (2.5\%); employers (0.8\%); and senior centers $(0.8 \%)$.

Results from our analysis indicate that differences existed in where caregivers got their information in the Mainland compared with Puerto Rico. Puerto Rican caregivers were more likely to get their information from the VA (50.0\%) compared with Mainland caregivers (19.2\%, $p<0.001)$. A trend toward greater Internet use in the Mainland vs Puerto Rico was noted $(23.1 \%$ vs $9.5 \%$, respectively, $p=0.08$ ).

\section{DISCUSSION}

The goal of this study was to gather information about the information needs, information receipt, and information sources of stroke caregivers within the VHA system. In addition, we examined the differences between Puerto Rican and Mainland caregivers, given the disparities in stroke burden for the former population. Overall, this study demonstrates that information is needed and this need is greater in some areas for Puerto Rican caregivers compared with Mainland caregivers.

This study highlights a relatively high need $(20 \%-$ $50 \%$ of caregivers) among all caregivers for information about managing behavior, keeping the veteran safe at home, managing emotional ups and downs, and protecting the veteran. Comparisons demonstrate that Puerto Rican caregivers report a greater need for information about managing behavior and keeping the veteran safe at home compared with Mainland caregivers. In addition, Puerto Rican caregivers have a greater unmet need for information about managing behavior, managing prescriptions and medications, and keeping the veteran safe at home. These findings suggest that Puerto Rican caregivers do indeed have a greater need for certain types of information related to their caregiving role.

Understanding where caregivers obtain the information they need about managing the caregiving role at home is useful. Caregivers in this study were most likely to get their information about stroke caregiving from their doctors, the VA, or the Internet. Puerto Rican caregivers were more likely to get their information from the VA. These findings highlight the importance of the VA in the information-dissemination process for caregivers of stroke survivors. Findings also indicate a need for promotion of the MyHealtheVet Web site as a source of information for caregivers.

The present study is part of a larger, ongoing survey study of informal caregivers of stroke survivors in the VHA system, and it has several limitations. First, this study is limited by the sample size of 120 caregivers. This sample restricted the number and type of analyses that we could perform to examine predictors of caregiver needs. As more data become available, we plan a second

Table 7.

Sources of caregiver information used by Mainland U.S. and Puerto Rican stroke caregivers.

\begin{tabular}{|c|c|c|c|c|c|}
\hline \multirow[b]{2}{*}{ Source } & \multicolumn{3}{|c|}{ Caregivers (\%) } & \multirow[b]{2}{*}{ Test Statistic ${ }^{*}$} & \multirow[b]{2}{*}{$p$-Value } \\
\hline & $\begin{array}{c}\text { Total } \\
(N=120)\end{array}$ & $\begin{array}{c}\text { Mainland } \\
(n=78)\end{array}$ & $\begin{array}{l}\text { Puerto Rico } \\
\quad(n=42)\end{array}$ & & \\
\hline Doctor & 32.5 & 35.9 & 26.2 & 1.17 & 0.28 \\
\hline Nurse/Other Health Professional & 13.3 & 14.1 & 11.9 & - & $>0.99$ \\
\hline Internet & 18.3 & 23.1 & 9.5 & - & 0.08 \\
\hline Employer & 0.8 & 0.0 & 2.4 & - & 0.35 \\
\hline Senior Center & 0.8 & 0.0 & 2.4 & - & 0.35 \\
\hline Department of Veterans Affairs & 30.0 & 19.2 & 50.0 & 12.31 & $<0.001$ \\
\hline Family & 8.3 & 6.4 & 11.9 & - & 0.32 \\
\hline Friend & 4.2 & 3.8 & 4.8 & - & $>0.99$ \\
\hline
\end{tabular}


analysis to examine predictors of information needs and create a more complete understanding of stroke caregivers' information needs and how clinicians can target this group for implementation projects.

Second, participation in the study required that the caregiver provide assistance with at least one ADL, but subjects were enrolled from a new stroke event occurring in FY2003, 2004, or 2005. Thus, some caregivers had been providing care for a longer period. Future analyses will analyze length of caregiving as it relates to information needs and information gaps between groups. Finally, caregivers were asked to retrospectively recall whether they had received information on social and clinical issues relating to stroke recovery. Recall can be affected not only by the length of time since the stroke event but also by the stress of the caregiving experience.

Despite these limitations, the present study offers important information for VHA stroke researchers and may help them understand the complex needs and patterns of information dissemination to stroke caregivers in the VHA system. That Puerto Rican caregivers have different needs and obtain information from different sources should be a starting point for implementation projects tailored to the needs of all stroke caregivers within the VHA system.

\section{CONCLUSIONS}

Educating caregivers and family members about stroke and the recovery process is important to the VA's mission. Our research indicates that caregivers of stroke survivors often do not have the information necessary to adequately manage the recovery process at home. We found that caregivers receive most of their information from their doctors, the VA, and the Internet. Given caregivers' reliance on VA resources, future work should focus on the dissemination of information to stroke caregivers through the VA.

\section{ACKNOWLEDGMENTS}

Dr. Hinojosa is now with the Medical College of Wisconsin.

This material was based on ongoing work supported by the VA Rehabilitation Outcomes Research Center of Excellence and a VA Nursing Research Initiative Award from the Health Services Research and Development Service (NRI 05-246 to Maude Rittman, RN, PhD).

The authors have declared that no competing interests exist.

\section{REFERENCES}

1. Schwamm LH, Pancioli A, Acker JE 3rd, Goldstein LB, Zorowitz RD, Shephard TJ, Moyer P, Gorman M, Johnston SC, Duncan PW, Gorelick P, Frank J, Stranne SK, Smith R, Federspiel W, Horton KB, Magnis E, Adams RJ, American Stroke Association's Task Force on the Development of Stroke Systems. Recommendations for the establishment of stroke systems of care: Recommendations from the American Stroke Association's Task Force on the Development of Stroke Systems. Stroke. 2005;36(3):690-703. [PMID: 15689577]

2. American Heart Association. Heart disease and stroke statistics—2005 update. Dallas (TX): American Heart Association; 2005.

3. Post-Stroke Rehabilitation Guideline Panel. Post-stroke rehabilitation. Clinical Guideline 16. AHCPR Publication 95-0662. Rockville (MD): U.S. Department of Health and Human Services; 1995.

4. Kwon S, Duncan PW, Reker DM, Lai SM, Studenski SA, Perera S, Alfrey C, Marquez J. Measuring health related quality of life in veterans with stroke. Poster presented at: Health Services Research and Development Service National Meeting; 2005 Feb 16-18; Baltimore, MD.

5. Veterans Health Administration. Veteran healthcare enrollment and expenditure projections. Washington (DC): Office of Policy and Planning (105); 2003.

6. Bian J, Oddone EZ, Samsa GP, Lipscomb J, Matchar DB. Racial differences in survival post cerebral infarction among the elderly. Neurology. 2003;60(2):285-90.

[PMID: 12552046]

7. Kissela B, Schneider A, Kleindorfer D, Khoury J, Miller R, Alwell K, Woo D, Szaflarski J, Gebel J, Moomaw C, Pancioli A, Jauch E, Shukla R, Broderick J. Stroke in biracial population: The excess burden of stroke among blacks. Stroke. 2004;35(2):426-31. [PMID: 14757893]

8. Casper ML, Barnett EB, Armstrong DL, Giles WH, Blanton CJ. Social class and race disparities in premature stroke mortality among men in North Carolina. Ann Epidemiol. 1997;7(2):146-53. [PMID: 9099402]

9. McGruder HF, Malarcher AM, Antoine TL, Greenlund KJ, Croft JB. Racial and ethnic disparities in cardiovascular risk factors among stroke survivors: United States 1999 to 2001. Stroke. 2004;35(7):1557-61. [PMID: 15192252]

10. Sheinart KF, Tuhrim S, Horowitz DR, Weinberger J, Goldman $\mathrm{M}$, Godbold JH. Stroke recurrence is more frequent in Blacks 
and Hispanics. Neuroepidemiology. 1998;17(4):188-98. [PMID: 9701833]

11. Gillum RF. Epidemiology of stroke in Hispanic Americans. Stroke. 1995;26(9):1707-12. [PMID: 7660419]

12. Horner RD, Swanson JW, Bosworth HB, Matchar DB, VA Acute Stroke (VAST) Study Team. Effects of race and poverty on the process and outcome of inpatient rehabilitation services among stroke patients. Stroke. 2003;34(4):1027-31. [PMID: 12624220]

13. Kapral MK, Wang H, Mamdani M, Tu JV. Effect of socioeconomic status on treatment and mortality after stroke. Stroke. 2002;33(1):268-73. [PMID: 11779921]

14. Stineman MG, Ross RN, Hamilton BB, Maislin G, Bates $\mathrm{B}$, Granger CV, Asch DA. Inpatient rehabilitation after stroke: A comparison of lengths of stay and outcomes in the Veterans Affairs and non-Veterans Affairs health care system. Med Care. 2001;39(2):123-37. [PMID: 11176550]

15. Dorsey MK, Vaca KJ. The stroke patient and assessment of caregiver needs. J Vasc Nurs. 1998;16(3):62-67. [PMID: 9883149$]$

16. O’Connell B, Baker L. Managing as carers of stroke survivors: Strategies from the field. Int J Nurs Pract. 2004;10(3): 121-26. [PMID: 15149459]

17. Doty P. Family care of the elderly: The role of public policy. Milbank Q. 1986;64(1):34-75. [PMID: 3084932]

18. Anderson CS, Linto J, Stewart-Wynne EG. A populationbased assessment of the impact and burden of caregiving for long-term stroke survivors. Stroke. 1995;26(5):843-49. [PMID: 7740578]

19. Mausbach BT, Coon DW, Depp C, Rabinowitz YG, WilsonArias E, Kraemer HC, Thompson LW, Lane G, GallagherThompson D. Ethnicity and time to institutionalization of dementia patients: A comparison of Latina and Caucasian female family caregivers. J Am Geriatr Soc. 2004;52(7): 1077-84. [PMID: 15209644]
20. Clark M, Huttlinger K. Elder care among Mexican American families. Clin Nurs Res. 1998;7(1):64-81. [PMID: 9526315]

21. Phillips LR, De Ardon ET, Komnenich P, Killeen M, Rusinak R. The Mexican American caregiving experience. Hisp J Behav Sci. 2000;22(3):296-313.

22. Weiss CO, González HM, Kabeto MU, Langa KM. Differences in amount of informal care received by non-Hispanic whites and latinos in a nationally representative sample of older Americans. J Am Geriatr Soc. 2005;53(1):146-51. [PMID: 15667392]

23. Smith LN, Lawrence M, Kerr SM, Langhorne P, Lees KR. Informal carers' experience of caring for stroke survivors. J Adv Nurs. 2004;46(3):235-44. [PMID: 15066101]

24. O'Connell B, Baker L, Prosser A. The educational needs of caregivers of stroke survivors in acute and community settings. J Neurosci Nurs. 2003;35(1):21-28. [PMID: 12789718]

25. Rodgers H, Bond S, Curless R. Inadequacies in the provision of information to stroke patients and their families. Age Ageing. 2001;30(2):129-33. [PMID: 11395342]

26. Wellwood I, Dennis MS, Warlow CP. Perceptions and knowledge of stroke among surviving patients with stroke and their carers. Age Ageing. 1994;23(4):293-98. [PMID: 7976775]

27. Pinquart M, Sörensen S. Ethnic differences in stressors, resources, and psychological outcomes of family caregiving: A meta-analysis. Gerontologist. 2005;45(1):90-106. [PMID: 15695420]

28. Reker DM, Hamilton BB, Duncan PW, Yeh SC, Rosen A. Stroke: Who's counting what? J Rehabil Res Dev. 2001;38(2): 281-89. [PMID: 11392661]

Submitted for publication October 10, 2006. Accepted in revised form May 9, 2007. 